\title{
A Case Report on Revascularization of a Non-vital Immature Tooth
}

\author{
Arbind Rai*, Usha Ghiraiya \\ Department of Conservative Dentistry and Endodontics, People’s Dental College and Hospital, Kathmandu, Nepal \\ *Corresponding author: nibra2002@gmail.com
}

Received August 18, 2014; Revised September 01, 2014; Accepted September 18, 2014

\begin{abstract}
Revascularization is a treatment procedure that promotes the apexogenesis of a necrotic immature permanent tooth. This case report presents a successful management of a 9 year old male patient with a necrotic, immature maxillary right first premolar, via revascularization of the tooth. This procedure can be considered a promising approach over traditional methods.
\end{abstract}

Keywords: revascularization, biodentine, immature tooth

Cite This Article: Arbind Rai, and Usha Ghiraiya, "A Case Report on Revascularization of a Non-vital Immature Tooth.” International Journal of Dental Sciences and Research, vol. 2, no. 5A (2014): 5-7. doi: 10.12691/ijdsr-2-5A-2.

\section{Introduction}

Conventional methods of root canal treatment of a necrosed immature tooth has always been found to be problematic $[1,2,3]$. Better alternative to these cases, even when the tooth exhibit periapical pathology, is offered by revascularization procedure [4].

Revascularization procedures attempt at preserving the vitality of remaining dental pulp stem cells and mesenchymal stem cells of the apical papilla resulting in the completion of root maturation i.e. elongation of root length with an increase in root dentin thickness [5], [6]. Further, positive response to vitality test has also been demonstrated [7]. Though being technically simple, with less chances of immune rejection, it is still not clear whether the phenotype of the regenerated tissue resembles dental pulp or not. The current case shows the possibility of revascularization in 9 year old maxillary right first premolar with necrotic pulp.

\section{Case History}

A 9 year old boy was referred to the Department of Conservative Dentistry and Endodontics at People's Dental College and Hospital, Kathmandu, Nepal for the management of a non-vital tooth with open apex. According to the patient's clinical record, he had experienced pain in his upper right back region of jaw since 2 months. He visited a general dentist for the treatment and the tooth was treated with extirpation of inflamed pulp tissues to relieve the symptoms and referred to higher center for apexification. His medical history was not significant.

On extraoral examination, no significant findings were noted. Intraoral examination revealed zinc oxide eugenol restoration on maxillary right first premolar and the intraoral periapical radiograph revealed maxillary first premolar with an open apex, thin dentinal walls and a file up to the apical extent of the tooth(Figure 1).

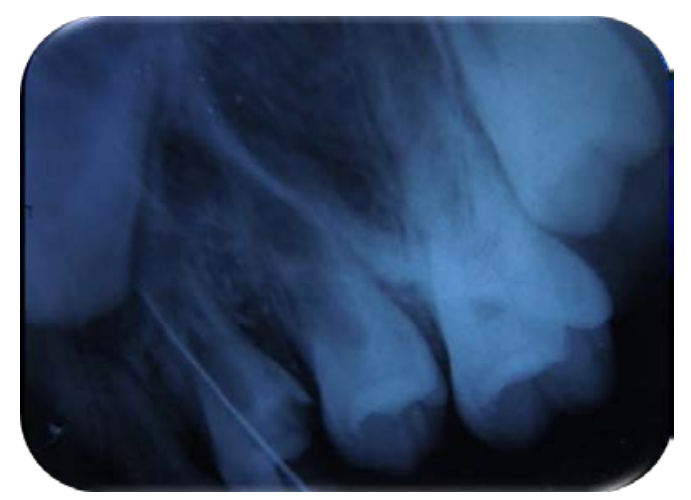

Figure 1. Initial radiograph

At the same appointment, the tooth was re-entered using an Endo Access bur (Dentsply Maillefer, Switzerland) in a high-speed air turbine handpiece (NSK PANA AIR, Nakanishi Inc., Japan) with copious irrigation. Proper isolation was maintained, copious amount of $1 \%$ $\mathrm{NaOCl}$ (Prime Dental, India) was used for irrigation and no endodontic instruments were used. The canal was dried with paper points and a 3 mix antibiotic paste (Minocycline, Ciprofloxacin and Metronidazole) in 1:1:1 concentration (by weight) was placed using propylene glycol as vehicle. The orifice was plugged with a sterile cotton pellet and access sealed with resin modified glass ionomer cement (Fuji II LC, Japan). After 3 weeks, patient returned with no further complain of pain or any sort of discomfort. The tooth was re-entered, with consideration given in maintaining isolation and infiltrated with LA (2\% xylocaine) without adrenaline. A sterile \# 10 file (Mani, Japan) was used to induce bleeding by instrumenting the 
periapical area in excess of the working length noted in the previous clinical records by $2 \mathrm{~mm}$. When bleeding was noticed in the canal, a small, moist cotton pellet was used to plug the canal, about 2-3 mm below orifice, and restrict the clot formation. Blood clot was allowed to form for 15 minutes in the canal and biodentine (Septodont, USA) was placed over it, that extended $1 \mathrm{~mm}$ over the orifice into the pulp chamber. The canal was sealed with triple barrier in the form of biodentine, GIC (Shofu Dental Supplies (Sanghai Co., Ltd, China) and Composite resin (Ceram.X duo, Dentsply, UK) During 3 months follow up, the tooth became discolored but the radiographic evidence of apexogenesis was evident.

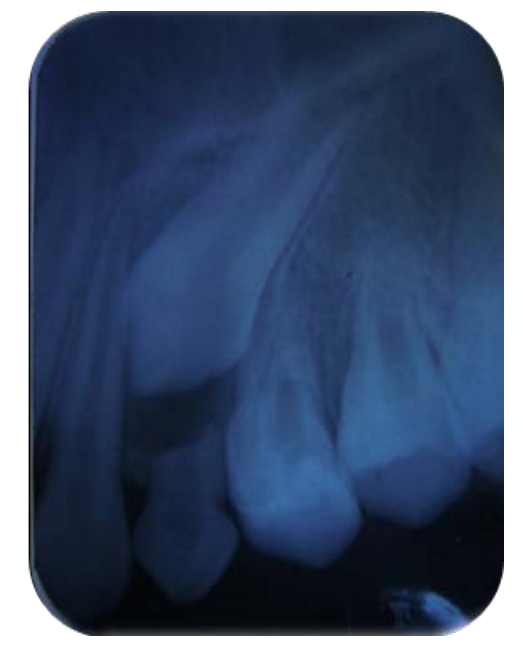

Figure 2. After 1 month

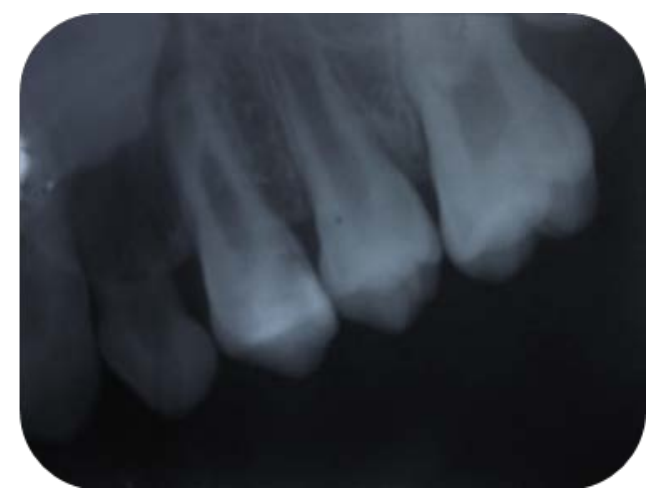

Figure 3. After 6 months

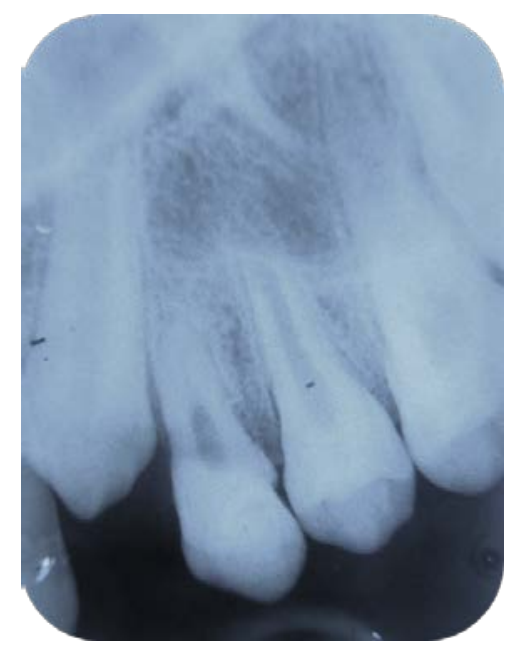

Figure 4. After 1 year
The patient was followed up at 1, 6 and 12 months revealing closure of apex along with thickened dentinal wall (Figure 2, Figure 3, Figure 4). The follow up visit could not confirm the tooth response to either thermal or electric stimulus when tested. To reconfirm the response, the restorative materials were removed from the occlusal aspect and the calcified structure exposed. The tooth was then tested for responsiveness with the help of electric pulp sensibility tester, via bridging method, and the tooth responded.

\section{Discussion}

Revascularization treatment provide a favorable alternative by the development of a longer and thicker root, less susceptible to fracture $[6,8]$ and with a possibility of gaining vitality. In the case of a developing tooth, the dental papilla at the apex may contain more stem cells than a mature tooth and therefore possesses a greater potential to rebuild the lost pulp tissue and continue the root maturation [5].

Therefore, for revascularization to succeed, critical factor that needs to be considered are the viability of the remaining survived pulp tissue and the stem cells of the apical papilla. Therefore, to preserve these essential stem cells, a protocol of 'no canal instrumentation' throughout the revascularization procedure needs to be followed $[5,6,9]$.

Even though, calcium hydroxide being most commonly used intra-canal medicament, recommendations are made to avoid it as an intra-canal medicament to prevent damage to the remaining pulp tissue, apical papilla and HERS. It was found that a combination of ciprofloxacin, metronidazole, and minocycline ( $25 \mu \mathrm{g}$ each per milliliter of paste) was able to sterilize infected root dentin in vitro [10]. It was judged to be an effective disinfectant in vivo [11] and has been successfully used in regenerative endodontics [6]. The antibiotic paste used in the study contained $100 \mathrm{mg}$ of each of the three antibiotics in a total volume of $0.5 \mathrm{~mL}$ [7].

$1 \% \mathrm{NaOCl}(\sim 1 \%)$ was prepared by diluting 1 part of $5.25 \% \mathrm{NaOCl}$ with 3 parts of water. Vehicle used was Propylene glycol due to its potential for rapid and effective delivery of intracanal medicaments into root dentin [12].

Apart from disinfection, to promote cell growth and differentiation, an appropriate scaffold is needed. Studies had also underlined role of growth factors in angiogenesis, recruitment of progenitor cells, cell differentiation and finally mineralization in the pulp area beneath the biomaterial. Hence, inducing blood clot is considered a scaffold as well as a source of growth factors that facilitates the repair and regeneration of tissues into the canal $[13,14]$.

Long-term sealing is ensured by placing triple seal of biodentin, followed by GIC and Composite resin. Marginal sealing achieved by Biodentin was equivalent to that of adhesive restoration without any surface treatment or adhesive system used [15]. Placing biodentin in the innermost layer prevents the material from erosion and directly withstanding occlusal load, contributing to its increased marginal sealing as well as ensuring prevention of recurrent pulpitis. 
Biodentine significantly increases TGF- $\beta 1$ secretion from pulp cells which consequently induce odontoblast differentiation and mineralization [16]. In this case, the material was placed more superficial than those recommended in various other studies because placing the coronal edge of material 1 to $2 \mathrm{~mm}$ apical to the CEJ allowed for more root development than placing it up to 3 to $4 \mathrm{~mm}$ apically [7].

In this case, signs of root maturation with apex closed completely along with thickened root dentinal wall and when tested, the tooth responded to electric pulp tester after 12 months of follow up period. The radiographic evidence of increased root thickness might be due to dentin, cementum or bone [5] and the present findings is insufficient to distinguish among these possibilities. Studies had also shown that the tooth regaining its responsiveness to electric pulp sensibility testing even after 18-month follow up period after remaining asymptomatic all the time [17]. Further, in spite of the possibility of pulp tissues to re-enter the canal, histological examination is required to confirm it [18].

\section{Conclusion}

The outcome of this case report suggests that the conservative treatment approach can create a suitable environment for pulp regeneration and result in root maturation via regaining the vitality of the tooth. This leads to an added advantage of increased strength of the tooth, with lesser financial burden as well as better psychological well-being to the patient.

\section{Conflict of Interests}

The authors (Dr. Arbind Rai and Dr. Usha Ghiraiya) declares that there is no conflict of interests regarding thepublication of this article.

\section{References}

[1] Rafter M. Apexification: a review. Dental traumatology: official publication of International Association for Dental Traumatology. 2005; 21(1): 1-8.

[2] Camp J FA. In: Pediatric endodontics: endodontic treatment for the primary and young permanent dentition. Cohen S, Hargreaves K, Keiser K, eds. Pathways of the pulp. 9th ed. St Louis: Mosby Elsevie. 2006: 822-82.

[3] Andreasen JO, Farik B, Munksgaard EC. Long-term calcium hydroxide as a root canal dressing may increase risk of root fracture. Dental traumatology: official publication of International Association for Dental Traumatology. 2002; 18(3): 134-7.

[4] Shah N, Logani A, Bhaskar U, Aggarwal V. Efficacy of revascularization to induce apexification/apexogensis in infected, nonvital, immature teeth: a pilot clinical study. Journal of endodontics. 2008; 34(8): 919-25.

[5] Chueh LH, Huang GT. Immature teeth with periradicular periodontitis or abscess undergoing apexogenesis: a paradigm shift. Journal of endodontics. 2006; 32(12): 1205-13.

[6] Jung IY, Lee SJ, Hargreaves KM. Biologically based treatment of immature permanent teeth with pulpal necrosis: a case series. Journal of endodontics. 2008; 34(7): 876-87.

[7] Petrino JA, Boda KK, Shambarger S, Bowles WR, McClanahan SB. Challenges in regenerative endodontics: a case series. Journal of endodontics. 2010; 36(3): 536-41.

[8] Huang GT, Sonoyama W, Chen J, Park SH. In vitro characterization of human dental pulp cells: various isolation methods and culturing environments. Cell and tissue research. 2006; 324(2): 225-36.

[9] Iwaya SI, Ikawa M, Kubota M. Revascularization of an immature permanent tooth with apical periodontitis and sinus tract. Dental traumatology: official publication of International Association for Dental Traumatology. 2001; 17(4): 185-7.

[10] Hoshino E, Kurihara-Ando N, Sato I, Uematsu H, Sato M, Kota K, et al. In-vitro antibacterial susceptibility of bacteria taken from infected root dentine to a mixture of ciprofloxacin, metronidazole and minocycline. International endodontic journal. 1996; 29(2): 125-30.

[11] Er K, Kustarci A, Ozan U, Tasdemir T. Nonsurgical endodontic treatment of dens invaginatus in a mandibular premolar with large periradicular lesion: a case report. Journal of endodontics. 2007; 33(3): 322-4.

[12] Cruz EV, Kota K, Huque J, Iwaku M, Hoshino E. Penetration of propylene glycol into dentine. International endodontic journal. 2002; 35(4): 330-6.

[13] Neha K, Kansal R, Garg P, Joshi R, Garg D, Grover HS. Management of immature teeth by dentin-pulp regeneration: a recent approach. Medicina oral, patologia oral y cirugia bucal. 2011; 16(7): e997-1004.

[14] Thibodeau B, Teixeira F, Yamauchi M, Caplan DJ, Trope M. Pulp revascularization of immature dog teeth with apical periodontitis. Journal of endodontics. 2007; 33(6): 680-9.

[15] J. Déjou AR, J Colombani \& I. About. Physical, Chemical and Mechanical Behavior of a New Material for Direct Posterior Fillings. European Cells and Materials. 2005 Vol. 10. (Suppl. 4): page 22.

[16] Laurent P, Camps J, About I. Biodentine(TM) induces TGF-beta1 release from human pulp cells and early dental pulp mineralization. International endodontic journal. 2012; 45(5): 439-48.

[17] Thomson A, Kahler B. Regenerative endodontics - biologicallybased treatment for immature permanent teeth: a case report and review of the literature. Australian Dental Journal. 2010; 55(4): 446-52.

[18] Ritter AL, Ritter AV, Murrah V, Sigurdsson A, Trope M. Pulp revascularization of replanted immature dog teeth after treatment with minocycline and doxycycline assessed by laser Doppler flowmetry, radiography, and histology. Dental traumatology: official publication of International Association for Dental Traumatology. 2004; 20(2): 75-84. 